\title{
DELIMITAÇÃO DA ÁREA DE PRESERVAÇÃO PERMANETE NA REPRESA DA USINA HIDRELÉTRICA DE FURNAS COM O USO DE TÉCNICAS FOTOGRAMÉTRICAS
}

Luiza Procópio Tostes Teixeira - luizaprocópio@gmail.com

Universidade Federal de Minas Gerais

Marcela Nishimoto - marcelanishimoto@gmail.com

Centro Federal de Educação Tecnológica de Minas Gerais

Carlos Alberto Trindade - carlos.cat@dpf.gov.br

Setor Técnico-Científico da Polícia Federal em Minas Gerais

Julia Chaves Silva Nunes - juliachaves.nunes@gmail.com

Universidade Federal de Minas Gerais 


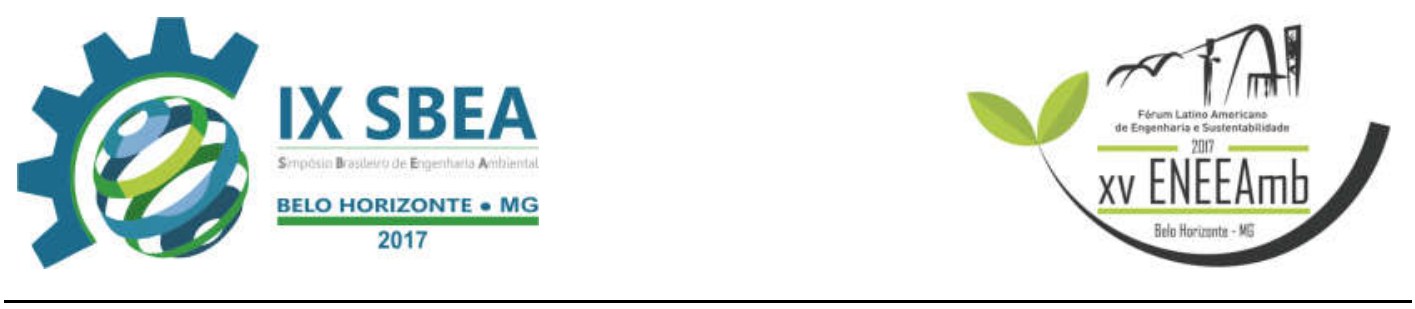

\section{RESUMO}

A Usina Hidrelétrica de Furnas (UHE Furnas) foi construída com objetivo de prover energia elétrica para a região sudeste do Brasil. A construção da barragem desencadeou uma valorização dos terrenos ao seu redor por sua beleza cênica, o que provocou uma intensa ocupação da área, algumas vezes de forma desordenada. $\mathrm{O}$ Código Florestal brasileiro, Lei 4.771 de 1965, considera Área de Preservação Permanente (APP) as florestas e demais formas de vegetação natural situadas ao redor de lagoas, lagos ou reservatórios d'água naturais ou artificiais, dentre outras. No caso da UHE Furnas, pela reforma do Código Florestal promulgada pela Lei $\mathrm{n}^{0} 12.651$ de 2012, sua área de APP, conforme o Art. 62, é a distância entre o nível máximo operativo normal (NMO) e a cota máxima maximorum (CMM). A realização de construções na área desapropriada da represa da UHE Furnas e na APP é crime de usurpação de bens da União e Crime ambiental, respectivamente, passível da necessidade de elaboração de laudos pela Perícia Criminal Federal. Ao longo dos anos a determinação dos limites de APP vem sendo realizada por meio da medição de pontos de controle com equipamentos topográficos ou geodésicos. Esta forma de determinação de APP é extremamente precisa, porém é demorada no caso de se trabalhar em grandes extensões. O uso da fotogrametria surgiu como um método alternativo de determinação de APP com boa precisão e com um menor tempo de execução. A fotogrametria digital consiste na reconstrução de um espaço tridimensional, a partir de um conjunto de imagens bidimensionais digitalizadas. Essas imagens são obtidas por meio de veículos aéreos, e após o processamento das fotografias e pontos de controle coletados em campo, os resultados gerados são a ortofoto e o modelo digital de elevação (DEM). A partir de tais informações, é possível obter as curvas de nível do terreno, para identificação das curvas de interesse e delimitação da APP. O uso das técnicas fotogramétricas mostrouse uma alternativa viável para uso nos trabalhos da área ambiental pela sua simplicidade de uso, com relativo baixo custo dos equipamentos utilizados, e boa qualidade dos dados gerados.

Palavras-chave: Área de Preservação Permanente, Fotogrametria, Ortofoto, Modelo Digital de Elevação. 


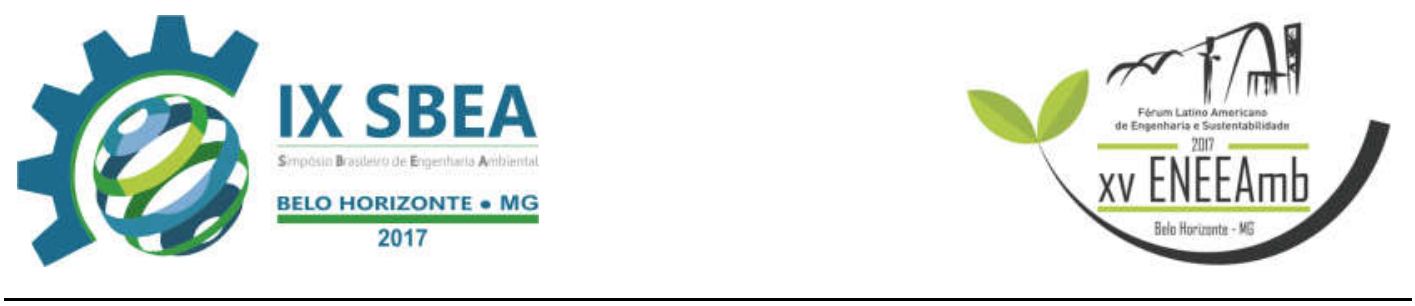

\section{INTRODUÇÃO/OBJETIVO}

A Usina Hidrelétrica de Furnas (UHE Furnas) tinha o objetivo de fornecer energia elétrica para os centros econômicos do sudeste brasileiro. Para sua construção, em 1958, foi necessário o alagamento de uma área de cerca de $1440 \mathrm{~km}^{2}$, armazenando um volume total de 22,95 bilhões $\mathrm{m}^{3}$ de água e abrangendo um total de 34 municípios, sendo eles: Aguanil, Alfenas, Alpinópolis, Alterosa, Areado, Boa Esperança, Cabo Verde, Camacho, Campo Belo, Campo do Meio, Campos Gerais, Cana Verde, Candeias, Capitólio, Carmo do Rio Claro, Coqueiral, Cristais, Divisa Nova, Elói Mendes, Fama, Formiga, Guapé, Ilicínea, Itapecerica, Lavras, Nepomuceno, Paraguaçu, Perdões, Pimenta, Ribeirão Vermelho, São João Batista do Glória, São José da Barra, Três Pontas e Varginha. Originou-se assim a Represa de Furnas. (SANTOS et al., 2003).

O nível de armazenamento do lago da UHE Furnas (nível máximo operativo NMO) é de 768 metros acima do nível do mar, a cota máxima maximorum (CMM), que corresponde ao nível de água mais elevado para o qual a barragem foi projetada, é de 769,3 metros e a cota de desapropriação (CD) corresponde à cota 769,0 m. Essa cota corresponde às terras em que o governo federal desapropriou no entorno da represa. Portanto, regiões com cotas inferiores a 769,0 metros são áreas da União.

Com a construção da barragem, iniciou-se um intenso processo de especulação imobiliária nos arredores da represa devido a beleza cênica do local e do lazer proporcionado pelo lago. Porém, a ocupação no entorno, muitas vezes, foi desenfreada e desordenada. (GONDIM et al. 2009)

De acordo com o Art. $2^{\circ}$ da Lei no 4771 de 1965 (Código Florestal), consideramse Área de Preservação Permanente (APP) as florestas e demais formas de vegetação natural situadas ao redor de lagoas, lagos ou reservatórios d'água naturais ou artificiais, dentre outras. Em 20 de março de 2002, a Resolução CONAMA nº 302 estabeleceu, no Art. $3^{\circ}$, que a APP dos reservatórios artificiais seria mensurada em trinta metros para os reservatórios artificiais situados em áreas urbanas consolidadas e cem metros para áreas rurais, a partir do nível máximo normal (NMO). Além disso, no Art. $4^{\circ}$, definiu-se a 

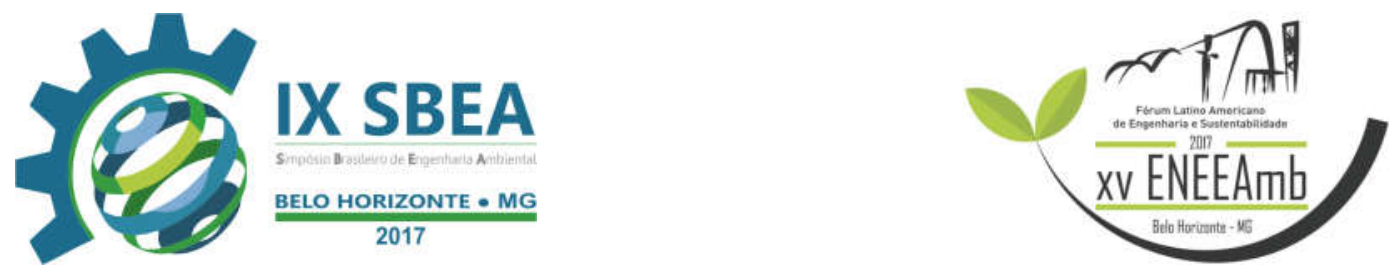

obrigatoriedade da elaboração de plano ambiental de conservação e uso do seu entorno, dentre outras medidas.

A reforma do Código Florestal entrou em vigor através da Lei $n^{\circ} 12.651$ de 2012, e determinou, no seu Art. 62, que a APP de reservatórios artificiais de água destinados a geração de energia ou abastecimento público que foram registrados ou tiveram seus contratos de concessão ou autorização assinados anteriormente à Medida Provisória no 2.166-67, de 24 de agosto de 2001, será a distância entre o nível máximo operativo normal (NMO) e a cota máxima maximorum (CMM). Assim, para a represa de Furnas a APP ficou definida na faixa entre as cotas 768,0 metros e 769,3 metros.

Por ser um bem da União, as determinações das invasões em APP do lago de Furnas, muitas vezes, demandam a elaboração de laudos pela Perícia Criminal Federal para elucidação do fato. A perícia criminal atua de forma idônea e se baseia em exames, vistorias e em provas materiais de qualidade para mensurar os danos antrópicos causados ao meio ambiente. Para tal são aplicadas técnicas e ferramentas compatíveis com os padrões de qualidade exigidos.

Há alguns anos, os trabalhos de determinação de APP em represas eram realizados com uso somente de equipamentos topográficos (estação total) ou geodésicos (receptores GNSS - Global Navigation Satellite Systems). Tais equipamentos possibilitam a obtenção de resultados bastante precisos, porém o emprego destas técnicas exige um tempo maior de execução, com necessidade da realização da medida de um grande número de pontos de campo para determinação detalhada do terreno para a realização dos Laudos Periciais.

O uso de imagens satelitais para a definição do período de ocorrência do delito, já se encontra com seu uso consolidado nos diversos trabalhos desenvolvidos. Entretanto, essas imagens nem sempre possuem a qualidade desejada ou época apropriada para a realização de determinados trabalhos.

Segundo Coelho \& Brito (2007) a fotogrametria consiste na reconstrução do espaço tridimensional a partir de imagens bidimensionais digitais. A partir da obtenção das fotografias, são coletadas informações de campo para o georreferenciamento destas fotografias de forma a se gerar ortofotos (fotografias eivadas de distorções) e o modelo digital do terreno. A Fotogrametria vem sendo utilizada em casos específicos, como 

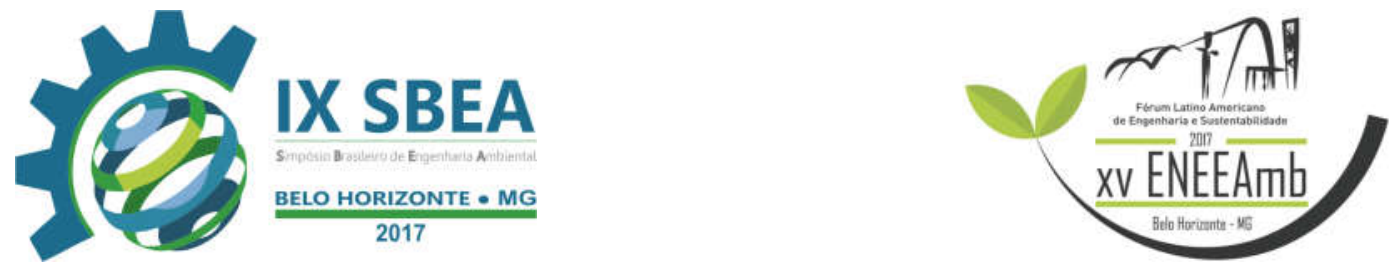

uma ferramenta a mais na execução dos exames periciais na área ambiental, tais como a determinação de Área de Preservação Permanente (APP) em represas, a mensuração de volumes de minerais extraídos e o cálculo de áreas desmatadas.

O presente trabalho visa apresentar aplicação da Fotogrametria nas perícias realizadas pelo Setor Técnico-Científico da Polícia Federal de Minas Gerais, para delimitação da APP do Reservatório de Furnas, descrever as possibilidades e limitações do emprego da técnica, citar as formas de obtenção das fotografias e mostrar a qualidade do material produzido.

\section{METODOLOGIA}

\subsection{Veículos utilizados para obtenção das fotografias aéreas.}

A escolha do veículo aéreo para tomada das fotografias é função direta da área total a ser periciada, das condições de acesso a estes locais e das condições logísticas de emprego de cada um. Dispõe-se no Setor Técnico-Científico de Minas Gerais (SETEC/MG) de um drone multirotor (Figura 1) desenvolvido totalmente pelos Peritos Criminais e de um Phantom 3 Professional. A Unidade Técnico-Científica de Uberlândia (UTEC/UDI) dispõe de um drone eBee asa fixa (Figura 2) e, de acordo com o fabricante, pode ser utilizado em aéreas de até $12 \mathrm{~km}$ quadrados. Em regiões de difícil acesso ou locais onde o trabalho abrange distâncias superiores à capacidade dos VANTs, são empregados helicópteros da Polícia Federal da Coordenação de Aviação Operacional (CAOP/DF) sediada em Brasília. Sob o helicóptero é acoplada uma câmera profissional fixa por meio de ventosas (Figura 3).

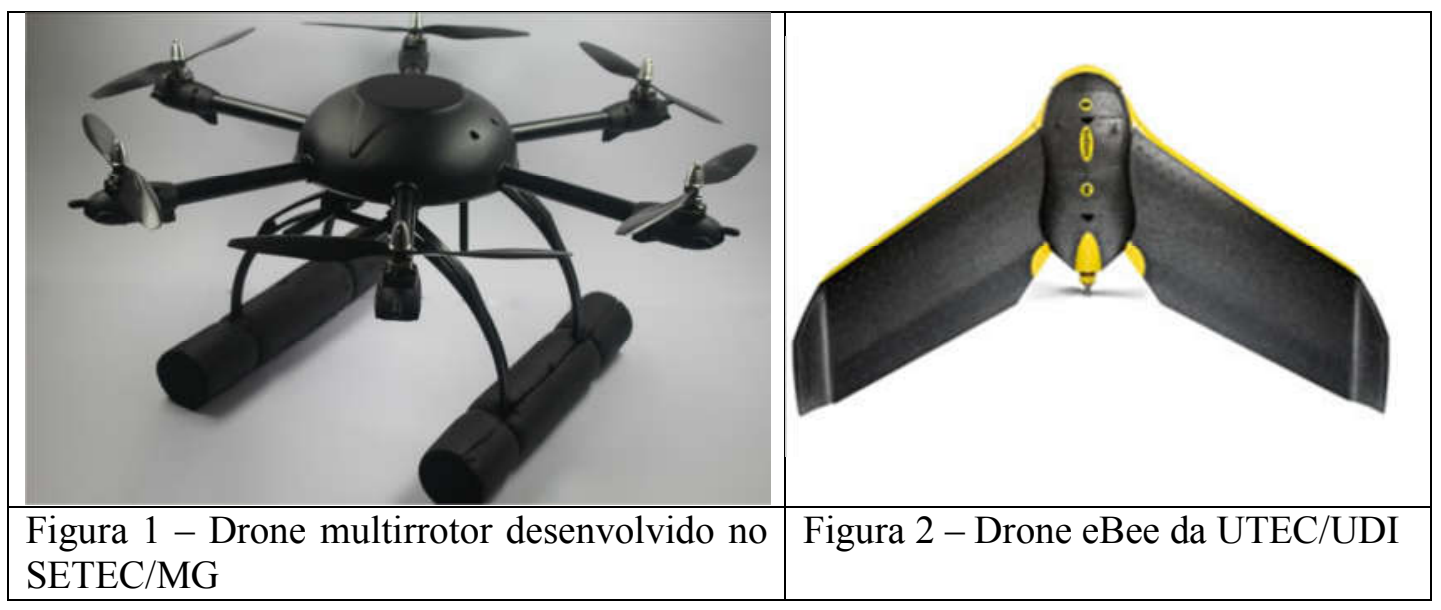



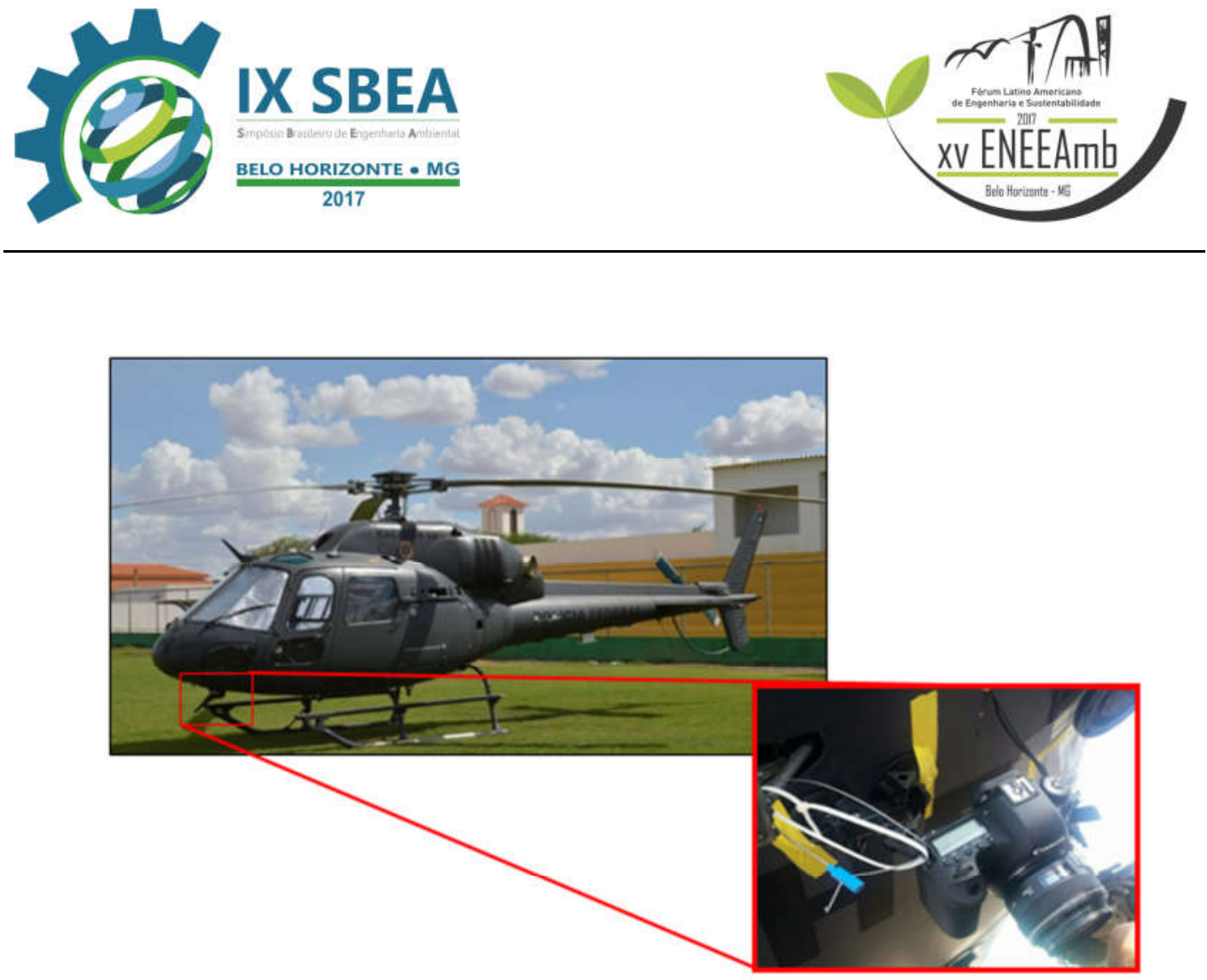

Figura 3 - Helicóptero da Polícia Federal da Coordenação de Aviação Operacional, com uma câmera Canon EOS 6D acoplada.

\subsection{Planejamento de voo}

Independentemente da plataforma de voo adotada, há a necessidade de se realizar o plano de voo para a obtenção das fotografias de forma planejada, de acordo com os parâmetros desejados para obtenção das precisões necessárias para a execução das perícias ambientais. É a partir dele serão definidos os parâmetros básicos para captura das imagens aéreas. $\mathrm{O}$ eBee dispõe de plataforma proprietária da empresa SenseFly e não será objeto do presente trabalho por se traduzir em um software proprietário. As demais plataformas de aquisição de dados utilizam o aplicativo Mission Planner para o planejamento do voo. A Tabela 1 apresenta, por exemplo, os parâmetros da câmera fotográfica utilizada em um dos trabalhos de campo, bem como de outros parâmetros definidos para a execução dos sobrevoos. 

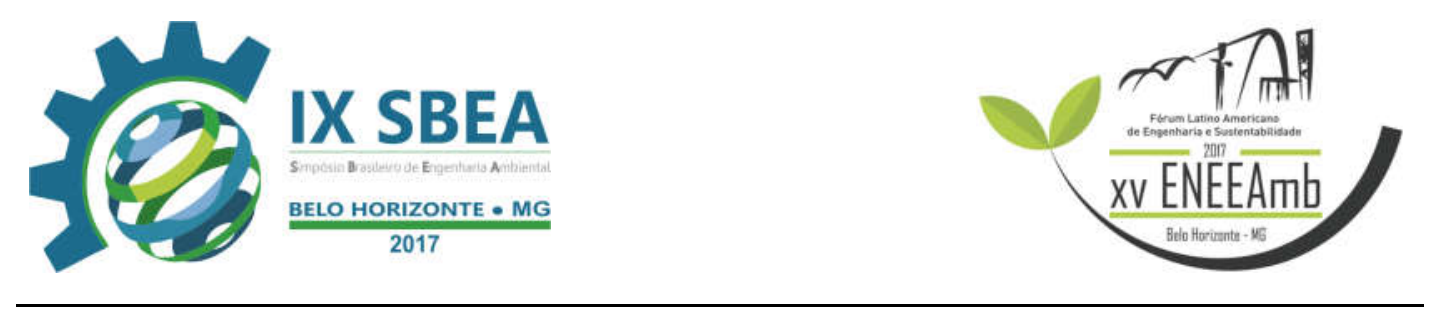

Tabela 1 - Parâmetros de entrada para planejamento de voo.

\begin{tabular}{|c|c|c|c|c|c|c|c|}
\hline \multirow[t]{2}{*}{$\begin{array}{l}\text { Câmera } \\
\text { Utilizada }\end{array}$} & \multirow{2}{*}{$\begin{array}{c}\text { Distância } \\
\text { focal } \\
\text { (mm) }\end{array}$} & \multicolumn{2}{|c|}{$\begin{array}{c}\text { Sensores da câmera } \\
(\mathrm{mm})\end{array}$} & \multirow[t]{2}{*}{$\begin{array}{l}\text { Altitude } \\
\text { (m) }\end{array}$} & \multirow[t]{2}{*}{$\begin{array}{l}\text { Velocidade } \\
\text { (m/s) }\end{array}$} & \multicolumn{2}{|c|}{ Sobreposição (\%) } \\
\hline & & Largura & Altura & & & Horizontal & Vertical \\
\hline $\begin{array}{c}\text { Canon EOS } \\
6 \mathrm{D}\end{array}$ & 24 & 36 & 24 & 120 & 12 & 80 & 70 \\
\hline
\end{tabular}

A partir dos dados de entrada descritos na Tabela 1, os dados de saída são gerados e determinam a resolução das imagens, número de fotografias, intervalo, em segundos, entre uma fotografia e outra, tempo de voo e número e de passagens.

\subsection{Processamento dos dados}

Após a realização do voo aerofotogramétrico, é necessária a determinação de pontos de controle em campo. Tais pontos de controle devem ser compatíveis com as precisões planoaltimétricas necessárias para o caso em que se necessita trabalhar. No SETEC/MG são utilizados receptores GNSS geodésicos da marca e modelo TRIMBLE R6, para obtenção das coordenadas latitudinais e longitudinais. Os pontos coletados em campo são processados por meio do aplicativo computacional Trimble Bussines Center 2 e em geral se utilizam métodos de rastreio que permite a precisão em torno de $5 \mathrm{~cm}$. Tais pontos coletados são utilizados na fase do processamento computacional para realizar o georreferenciamento dos dados gerados, colocando-se o modelo tridimensional, gerado pela fotogrametria, em escala em relação ao terreno original.

O processamento das fotografias, também denominado processamento fotogramétrico, é realizado com uso do aplicativo Agisoft Photoscan e, deste processamento, são obtidas ortofotos e modelos digitais de superfície. Os dados gerados não se traduzem necessariamente um modelo digital do terreno pelo fato de se modelar também as edificações existentes, a presença de árvores e vegetação e de outras construções porventura existentes. A partir do modelo tridimensional são geradas as curvas de nível referentes ao Nível Máximo Operativo (NMO), a Cota de Desapropriação (CD) e a Cota Máxima Maximorum (CMM) do reservatório da represa de Furnas. 


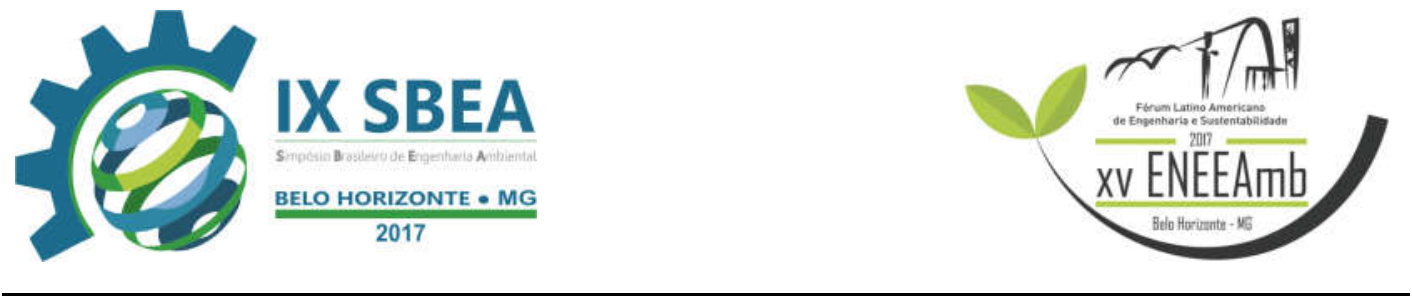

\section{RESULTADOS E DISCUSSÃO}

Após o processamento das fotografias obtidas e pontos de controle coletados em campo, os resultados gerados foram a ortofoto e o modelo digital de superfície (MDS). A partir de tais informações, foi obtido também as curvas de nível do terreno, para identificação das curvas de interesse, sendo elas a NMO, CMM e CD.

De acordo com a legislação vigente, a APP é a área entre a cota NMO e CMM. Portanto, após seleção das cotas de interesse, é possível quantificar a APP, conforme mostrado na Figura 4. Nesta mesma Figura são apresentadas outras informações como a cota de desapropriação e a faixa de 30m a partir do NMO para uso da Justiça caso se julgue necessário.

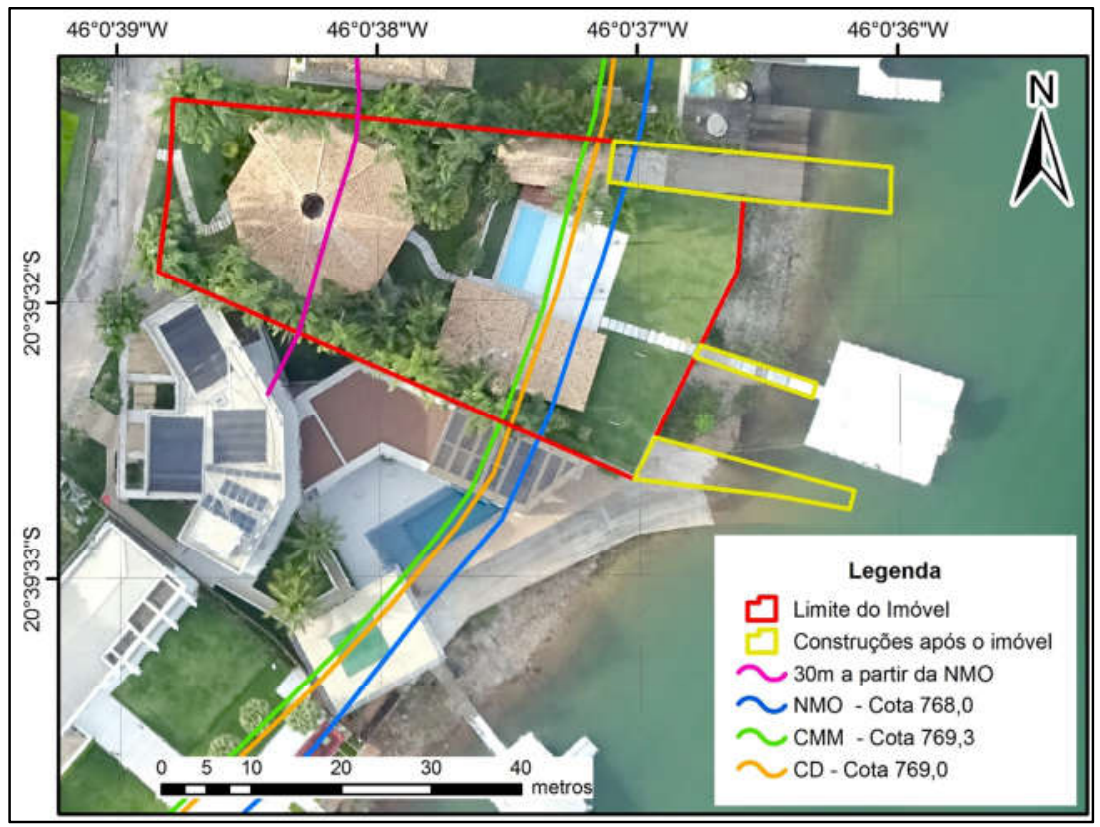

Figura 4 - Ortofoto de área periciada com os limites do imóvel e das cotas NMO, CMM, CD e faixa de $30 \mathrm{~m}$ a partir do NMO.

Métodos de determinação de APP com equipamento topográficos e geodésicos são mais precisos que utilizando Fotogrametria, entretanto exigem muito mais trabalho de campo, não geram ortofotos, necessitam de grande número de pontos de campo e há que se percorrer fisicamente o local a ser periciado, o que pode ser um problema em locais de imóveis de veraneio, em que os proprietários só são encontrados em suas propriedades em épocas de festas ou finais de semana. 


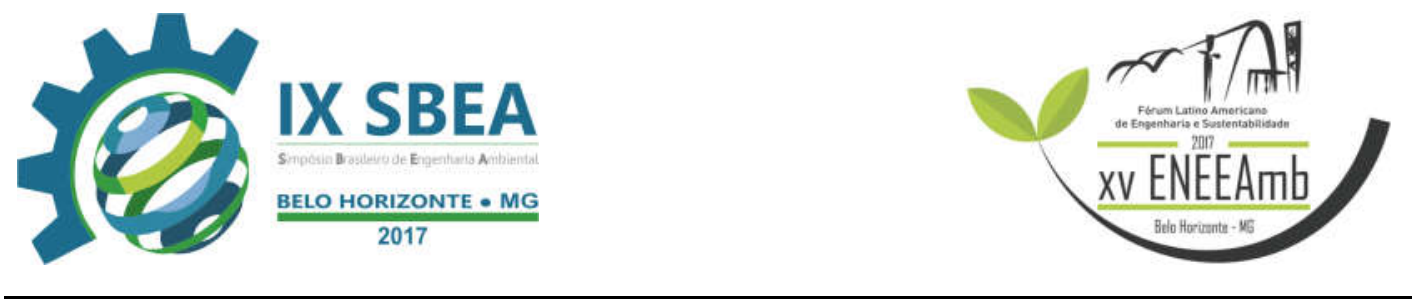

Nesse sentido, o uso da Fotogrametria possibilitou o levantamento de pontos geodésicos, a realização da cobertura aérea de vários imóveis ao mesmo tempo, sem a necessidade de adentrar os lotes questionados, e permitiu a obtenção de precisões cartográficas das ortofotos na ordem de 5 e $10 \mathrm{~cm}$, valores adequados para a maioria dos trabalhos comumente solicitados.

O uso da plataforma de aquisição das fotografias é função direta do tamanho da área a ser periciada e das condições de acesso. O helicóptero possui uma autonomia superior à dos drones de asa fixa (eBee) ou asa rotativa (multirotor), sendo possível percorrer uma área maior em um mesmo voo, além de possibilitar o uso de câmeras com maior resolução. Porém, o seu uso apresenta custo muito maior para a União, sendo que esta solução deve ser utilizada nos casos em que a o ganho de produtividade se justifique. Os Vants de asa fixa e rotativa apresentam a desvantagem de abranger regiões menores, porém o trajeto para obtenção das fotos, definido no plano de voo, é realizado de forma automática, tornando-os menos passíveis de erros, pois não depende exclusivamente do operador, como é o caso do helicóptero

\section{CONCLUSÕES/RECOMENDAÇÕES}

O uso das técnicas fotogramétricas apresenta simplicidade do seu uso, com relativo baixo custo dos equipamentos utilizados, em comparação aos métodos topográficos e tradicionais, e boa qualidade dos dados gerados. Ela vem sendo utilizada com sucesso na elucidação dos diversos crimes ambientais, tornando-se uma excelente alternativa para uso nos trabalhos da área ambiental.

Ao utilizar o helicóptero, recomenda-se que o operador seja treinado previamente para execução do voo, seguindo o planejamento, pois assim os erros de execução podem ser minimizados.

\section{REFERÊNCIAS BIBLIOGRÁFICAS}



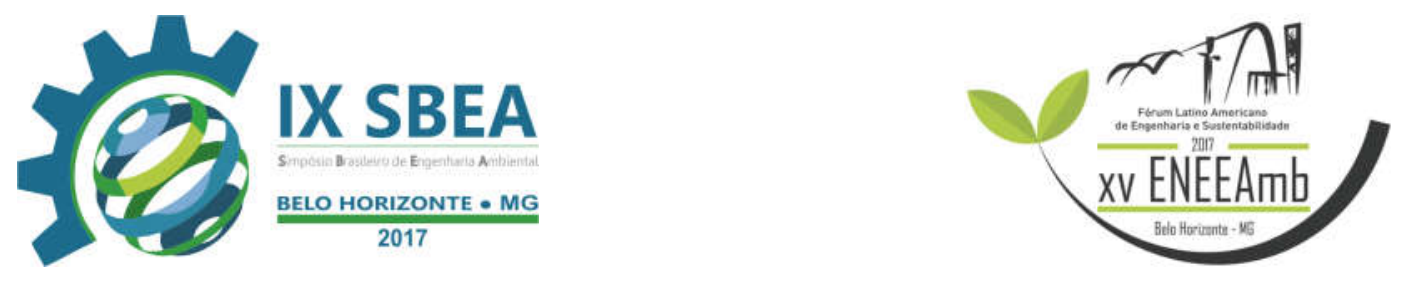

ANAC- Agência Nacional de Aviação Civil. RPAS - Sistemas de aeronaves remotamente pilotadas. Disponível em: http://www2.anac.gov.br/rpas/. Acesso em: 29maio. 2017.

BRASIL. Lei No ${ }^{\circ}$ 4.771, de 15 de Setembro de 1965. Institui o novo Código Florestal. Disponível em:< http://www6. senado. gov. br/legislacao/ListaPublicacoes. 15 de Setembro de 1965. Acesso em: 28 mai. 2016.

. CONAMA - Conselho Nacional do Meio Ambiente. Resolução n ${ }^{\circ}$ 302, de 20 de março de 2002. Dispõe sobre os parâmetros, definições e limites de Áreas de Preservação Permanente de reservatórios artificiais e o regime de uso do entorno. Ministério do Meio Ambiente, Brasília, DF, 20 mar 2002. Disponível em $<\mathrm{http} / /$ www.mma.gov.br/port/conama/res/res02/res30202.html >. Acesso em: 28 mai. 2016.

. Lei n. o 12.651 de 25 de maio de 2012. Dispõe sobre a proteção da vegetação nativa; altera as Leis nos 6.938, de 31 de agosto de 1981, 9.393, de 19 de dezembro de 1996, e 11.428, de 22 de dezembro de 2006; revoga as Leis nos 4.771, de 15 de setembro de 1965, e 7.754, de 14 de abril de 1989, e a Medida Provisória no 2.166-67, de 24 de agosto de 2001; e dá outras providências. Diário Oficial [da] República Federativa do Brasil, Brasília, DF, 25 mai. 2012. Disponível em $<$ http://www.planalto.gov.br/ccivil_03/_ato2011-2014/2012/lei/112651.htm>. Acesso em: 28 mai. 2016.

COELHO, L; BRITO, J. N.. Fotogrametria digital. Universidade do Estado do Rio de Janeiro. Ed. UERJ. Rio de Janeiro, 2007.

GONDIM, V. M.; ALEXANDRE, M. S.; DA CRUZ, M. L. B.. Uso do Sensoriamento Remoto na identificação da pressão antrópica na Lagoa do Catú- Aquiraz / Ceará. Natal, Brasil, abril, 2009.

SANTOS, A. H. M.; BORTONI, E. C.; RIBEIRO JUNIOR, L. U.; GARCIAA, M. A. R. A.. A exploração de reservatórios e os comitês de bacia: uma análise prospectiva para o caso da UHE de Furnas. Anais do XV Simpósio Brasileiro de Recursos Hídricos. Curitiba, PR, 2003.

TRINDADE, C. A; NISHIMOTO, M; TEIXEIRA, L.P.T.. Fotogrametria, uma realidade no combate ao crime ambiental no Brasil. In: Conferência Internacional de Ciências Forensics. Brasília, 2017. 